\title{
Análise dos determinantes salariais dos profissionais brasileiros produtores de conteúdo musical: uma visão pela abordagem da cauda longa
}

Wage determinants analysis of Brazilian professionals producers of music content: a view by a long tail approach

Vinícius Barbosa Teixeira Machado dos Santos (1) Sandro Eduardo Monsueto (2)

Bárbara Christina Pereira da Silva Carrijo ${ }^{(3)}$

(1) Universidade Federal de Goiás

(2) Universidade Federal de Goiás

(3) Universidade Federal de Goiás

\section{Abstract}

This article aims to compare the wages determinants for brazilian producers of musical content, splitted in two main groups: those who earn greater wages and those who earn minor wages. The aproach used to support this analysis is nominated The Long Tail, which was developed by Anderson (2006) and says that the music market can be divided in two parts, ie the hits market and the niches market. To percieve the effects of each variable over the hour-wage in those two different markets we use quantile regressions, applied over a typical mincerian wage function. The conclusions of this paper suggests that some of the wages determinants affect in a different ways the two specific music markets, described by the Long Tail aproach.

\section{Keywords}

Economics of culture; record industry; labour market; the Long Tail.

JEL Codes J44; J01.

\section{Resumo}

O objetivo deste artigo é a comparação dos determinantes dos salários dos produtores brasileiros de conteúdo musical, divididos entre aqueles que observam maiores e menores rendimentos de seu trabalho. A visão que dá suporte a esta análise é a abordagem da cauda longa, desenvolvida por Anderson (2006), que afirma existir dois mercados distintos para os produtos da indústria musical, ou seja, o mercado de grandes sucessos, os hits, e o mercado de nichos. Para captar os efeitos de cada variável sobre o salário-hora nesses diferentes mercados, são utilizadas regressões quantílicas, aplicadas a uma função de salários tipicamente minceriana. Os resultados mostram que alguns dos vários determinantes dos rendimentos dos trabalhadores possuem efeitos distintos sobre os dois grupos de profissionais.

\section{Palavras-chave}

economia da cultura; indústria fonográfica; mercado de trabalho; cauda longa.

Códigos JEL J44; J01. 


\section{Introdução}

A atividade de produção musical é considerada um dos elos fundamentais de toda a cadeia dos negócios criativos (Nakano, 2010). Isso decorre da participação direta ou indireta do produto fonográfico em diversas outras atividades, tais como cinema, teatro, dança, performances artísticas ao vivo, programas televisivos e radiofônicos, publicidade, entre outros. Segundo a Associação Brasileira dos Produtores de Discos (ABPD), entidade representativa das maiores empresas do setor fonográfico no Brasil, o volume mundial de negócios relacionados à produção musical movimentou, em 2005, US\$ 33,5 bilhões, desconsiderando-se receitas de apresentações ao vivo e outras provenientes de direitos autorais. $O$ pico referente às atividades das empresas associadas à ABPD movimentou $\mathrm{R}$ \$ 615,2 milhões em 2005, enquanto em 2009 as vendas de música relatadas pela Associação totalizaram R \$358,432 milhões. Já em 2015, as vendas digitais representavam cerca de $61 \%$ das receitas com música no Brasil (ABPD, 2010; 2016).

Contudo, pouco se tem estudado sobre o mercado de trabalho dos envolvidos na produção de conteúdo musical em meio às atuais transformações da indústria, principalmente com a expansão dos mercados alternativos de nicho. Faltam, portanto, estudos que analisem a determinação dos salários desses trabalhadores e se existem diferenças significativas entre os produtores de conteúdo de nichos e os envolvidos na dinâmica tradicional. Dessa forma, o presente estudo procura contribuir para preencher essa lacuna, através de uma análise específica do mercado de trabalho do setor produtor de conteúdo musical brasileiro, baseando-se nos apontamentos feitos pela abordagem conhecida por "cauda longa". Pretende-se, de forma específica, analisar se existem diferenças na determinação da renda entre os produtores de conteúdo musical ocupados na indústria de hits, ou seja, de maior sucesso musical e com maiores possibilidades de renda, e os ocupados nos mercados de nicho, onde são esperados os menores rendimentos.

Para a análise proposta são utilizados os dados da Pesquisa Nacional por Amostra de Domicílios (PNAD), entre os anos de 2002 e 2014. É empregada uma função de rendimentos do tipo minceriana, detalhada por meio de regressões quantílicas para captar os efeitos de cada determinante ao longo de vários pontos da distribuição de renda, relacionando esses pontos com a localização de cada trabalhador dentro da denominada cauda longa da indústria de produtos musicais. 
Este artigo está dividido em cinco seções. A primeira seção apresenta as principais características da denominada "cauda longa", enquanto a seguinte faz o relato de algumas análises empíricas sobre o mercado de trabalho cultural. A metodologia e os resultados das equações estimadas são discutidos em seguida. As considerações finais encerram o trabalho.

\section{0 mercado da cauda longa}

Até meados da década de 1990, o modelo padrão de distribuição de conteúdo de entretenimento era o broadcast, que consiste na transmissão de um tipo de programação para inúmeros receptores espalhados em um território, através de ondas de rádio, de televisão, telefonia, cabos ou satélite. Esse era um modelo que se mostrava eficiente em se tratando de transmissão de um tipo de produto a milhões de pessoas. Além disso, outros setores da indústria do entretenimento (música, filme, livro e imagem) eram vinculados à existência de suportes físicos (CD, DVD, livro) para distribuição de seus produtos.

Esse modelo de transação, muito próximo ao que Adorno e Horkheimer (1986) já denominavam de Indústria Cultural, devido à padronização dos objetos comercializáveis (Zuin, 2001) está sujeito a gargalos de ampliação da oferta, uma vez que existe tempo limitado para exibição da programação e de espaço para a exposição e estoque dos produtos físicos, além dos custos relacionados a esse tipo de atividade. Isso faz com que os programadores das grandes emissoras de rádio e televisão, por exemplo, e varejistas primem pela eficiência econômica ao escolher a programação a ser transmitida e quais mercadorias irão expor e estocar em suas lojas. Devido a isso, os agentes acabam concentrando esforços em poucos produtos com certa padronização e com maior potencial de inserção no grande público, os chamados hits. Dessa forma, produtos e conteúdos que não possuem um mercado potencial tão amplo têm espaço muito mais limitado nas prateleiras e grades de programação, chegando, inclusive, a não serem ofertados ou veiculados.

Entretanto, conforme mostra o estudo de Anderson (2006), avanços em tecnologia da informação vêm mudando esse paradigma dentro da indústria de entretenimento ao reduzir os custos de estoque, exposição e distribuição de conteúdo. Com a possibilidade de digitalização dos produtos 
dessa indústria, bem como o desenvolvimento de tecnologias de compactação de arquivos e o aumento na largura de banda para tráfego de dados via internet, os custos marginais de armazenamento e distribuição de conteúdo se aproximam de zero, aumentando as chances de encontro entre ofertantes e demandantes de mercados mais específicos. Como resultado, tem-se o que Anderson (2006) chama de "cauda longa".

Essa abordagem define o espaço dominado pelas grandes indústrias do setor, o mercado de hits, e descortina a expansão do comércio de música independente através dos mercados de nicho. A exploração dessa parte do mercado foi possível graças às evoluções observadas na informática e nas tecnologias de informação, que reduziram os custos de armazenagem e as barreiras à entrada para um grande número de artistas e pequenas empresas. O gráfico que representa o conceito de cauda longa, apresentado na Figura 1 , relaciona os dados sobre a quantidade consumida e a classificação, quanto à popularidade, dos bens encontrados em diversas lojas, reais ou virtuais. O eixo horizontal representa a posição de cada produto em um ranking de popularidade, sendo que quanto mais à esquerda mais popular. Dessa forma, na cabeça da curva, encontram-se os bens de consumo massificado, hits bastante difundidos. Estes são os bens comumente encontrados em lojas físicas e que são promovidos por grandes campanhas de marketing.

A continuação da curva leva até a região da cauda. Partindo desse ponto, encontram-se os bens adquiridos em menor quantidade, geralmente por nichos de consumidores (Anderson, 2006). Na cauda da curva pode ser encontrada uma infinidade de produtos, ofertados por um grande número de agentes. Esses produtos, em virtude do pequeno volume de vendas, dificilmente estariam disponíveis em lojas físicas, devido principalmente ao modelo econômico desses estabelecimentos. Em lojas virtuais, no entanto, as restrições de tamanhos de estoques e gastos com distribuição não configuram entraves à comercialização desses bens.

A formação da cauda longa ocorre devido à fragmentação dos mercados massificados, centrados em produtos de massa, para mercados de nicho. As produtoras e distribuidoras de conteúdos não precisam se ater aos produtos massificados, podendo avançar em direção ao atendimento da demanda que ocorre em nichos de mercado, e que se situa na cauda da curva. Com a evolução da produção e da distribuição através de meios digitais, bens que têm como alvo consumidores de nicho podem ser atrativos em termos econômicos, igualmente àqueles que concorrem pelo grande públi- 
co (Côrtes et al., 2008). Na verdade, segundo Anderson (2006), produtos de nicho estão concorrendo com bens massificados. Entretanto, sem a possibilidade de distribuição a baixos custos, os varejistas manteriam em seus estoques apenas produtos de grande apelo popular.

Figura $1 \mathrm{~A}$ curva que relaciona a procura por bens e sua popularidade, formando uma grande cauda, onde se situam os nichos de mercado

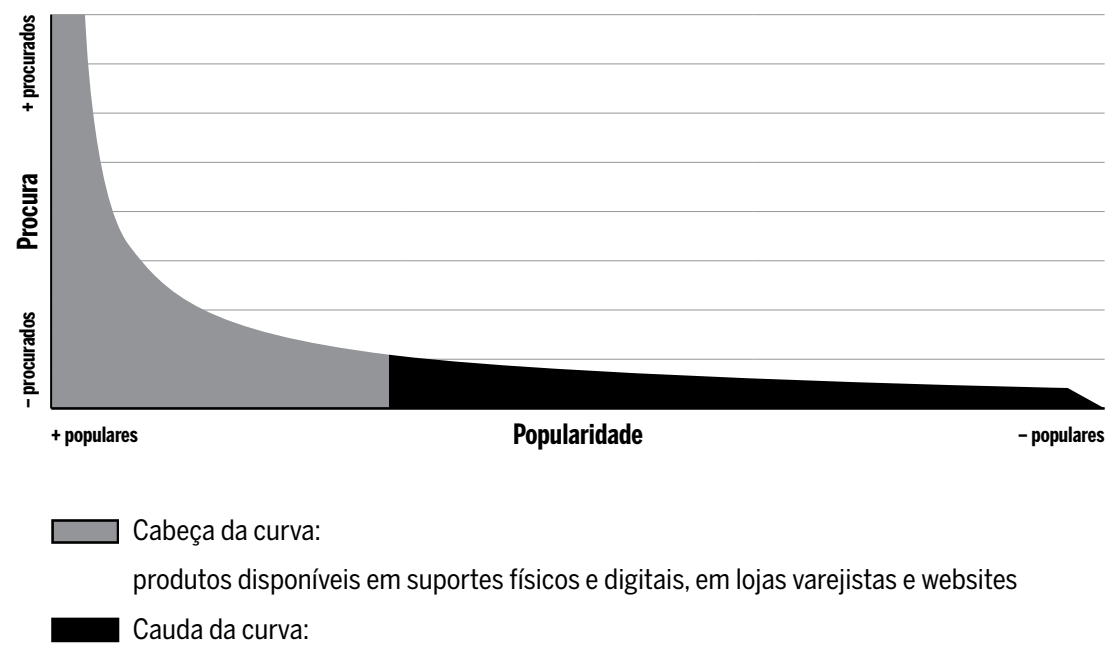

Fonte: Adaptação livre baseada em Anderson (2006).

Para Anderson (2006), o principal motivo econômico para a formação dos mercados de cauda longa reside na redução dos custos operacionais desses mercados. Tal redução tem ocorrido devido à ação do progresso tecnológico das ferramentas de produção e de distribuição, além do surgimento de mecanismos conectores entre a oferta e a demanda. Um exemplo dessa ação é o desenvolvimento do computador pessoal, que apresenta a capacidade de democratizar a elaboração de estúdios de produção de imagens, filme e música, possibilitando o surgimento de inúmeros produtores desses conteúdos, que antes sofriam com barreiras à entrada baseadas no acesso às tecnologias de produção.

Em conjunto com o computador pessoal, o rápido avanço da internet permitiu a democratização das ferramentas de distribuição, tornando os custos de distribuição de conteúdos digitais marginalmente iguais a zero. O aprimoramento da tecnologia de condensação de arquivos digitais de 
música, com a manutenção de considerável qualidade sonora, ${ }^{1}$ também contribui com o fenômeno (Patokos, 2008). Além disso, Anderson (2006) destaca a atuação dos "agregadores de cauda longa", ou empresas que oferecem serviços de coleta e organização de dados disponibilizados na internet, concentrando estoques dispersos de informação em um único lugar virtual. Essas empresas reduzem as barreiras entre ofertantes e demandantes de produtos e atuam tanto no mercado de bens digitais quanto no mercado de bens físicos, ${ }^{2}$ através da redução dos custos de obtenção de informações por parte dos usuários dos serviços oferecidos por tais empresas.

Por outro lado, os críticos do fenômeno da cauda longa apontam, entre outros elementos, a persistência de grandes sucessos de público no mercado cultural, devido ao fato de que os consumidores dos mercados de nicho também adquirirem produtos do circuito tradicional de distribuição comercial (Elberse, 2008). Por esse ponto de vista, mesmo os consumidores mais alternativos teriam certa resistência no momento de se expor a mercados e conteúdos de maior obscuridade, tendo a tendência a concentrar seus gastos também nos produtos mais populares. Ao mesmo tempo, é preciso considerar que alguns desses produtos de nicho não são necessariamente comercializados, sendo distribuídos de forma gratuita aos usuários, como os serviços e canais de vídeo da internet (Stallabrass, 2003). Para Quelch (2008), seria muito arriscado para as empresas deixar de investir nos grandes hits ou blockbusters, que ainda possuem elevada rentabilidade e conseguem atrair os melhores talentos, e passar a perseguir as micro-oportunidades incertas dos mercados de nicho.

A visão da cauda longa defendida por Anderson (2006) parece motivar um intenso debate sobre o acesso e o uso da cultura, principalmente no que diz respeito à denominada cibercultura ${ }^{3}$ e ao comércio eletrôni$\mathrm{co}^{4}$. Mesmo considerando as limitações da real expansão dos mercados de nicho como previsto por Anderson (2006), é possível constatar que a abordagem da cauda longa sobre o mercado musical estabelece a existência de dois segmentos. $\mathrm{O}$ primeiro trata dos hits, em que as atividades

1 O formato digital mp3.

2 São exemplos dessas empresas: Amazon, eBay, iTunes, Netflix, Google, Wikipedia, MySpace e Mercado Livre.

3 Uma síntese do debate sobre a cibercultura e a democratização da arte na internet pode ser vista, por exemplo, nos trabalhos de Rüdiger (2011) e Stallabrass (2003).

4 Oestreicher-Singer e Sundararajan (2012), por exemplo, realizam uma análise empírica do comércio eletrônico de livros na perspectiva da cauda longa. 
são dominadas pelas grandes empresas do setor, que mantém um modelo de negócios com baixa exposição aos riscos, explorando poucos produtos ofertados às grandes audiências (Côrtes et al., 2008). Já no segmento representado na cauda da curva, encontram-se os mercados de nicho, em que estão presentes pequenas empresas, além de artistas independentes, que conseguem disponibilizar seus produtos.

Contudo, a abordagem revela pouco sobre a dinâmica do mercado de trabalho de cada um desses segmentos do mercado musical. Por exemplo, quais são e como se comportam os determinantes dos rendimentos de cada tipo de trabalhador, atuante em cada área da curva descrita pela cauda longa? Essas informações não são encontradas no estudo de Anderson (2006), que se concentra em descrever modificações ocorridas no modelo de operação do mercado de bens musicais e outros mercados, nos quais o conceito de cauda longa pode ser aplicado Tentando lançar um pouco de luz sobre esse mercado, a próxima seção apresenta alguns estudos empíricos que, apesar de não mencionarem o modelo de mercado sugerido pela visão da cauda longa, tentam realizar algum tipo de caracterização geral dos trabalhadores do setor artístico e de seus rendimentos.

\section{Revisão empírica}

Inúmeros autores - Menguer (2006), Tolina (2007), Yúdice (2007), Diniz (2008), Popovic e Ratkovic (2013) - reportam sobre a dificuldade de se encontrar dados e teorias que buscam compreender as especificidades do mercado de trabalho artístico, uma vez que o trabalho de pesquisa em economia da cultura e das artes ainda não se tornou um campo consolidado das Ciências Econômicas. Pode-se afirmar que um importante ponto de partida foi realizado por Baumol e Bowen, em 1966, quando foram estudadas as estruturas de custos dos espetáculos ao vivo (Tolila, 2007). Com relação ao mercado de trabalho especificamente, a grande maioria dos estudos surgiu ao longo dos últimos 20 anos, sendo ainda mais recente para o caso brasileiro.

Análises internacionais tais como as de Menger (2006) e Benhamou (2007), por exemplo, encontram que uma das características desse mercado de trabalho é a descontinuidade e a incerteza quanto à existência de demanda. Benhamou (2007) mostra ainda, com base nos dados censitários 
franceses, que, quando comparados com outros trabalhadores de mesmo nível de instrução, os artistas profissionais são remunerados de maneira inferior. Para Menger (2006), outras características desses trabalhadores são a faixa etária mais jovem e a maior escolaridade, além da predominante presença dentro das regiões metropolitanas. Este último autor destaca ainda que, para o caso dos Estados Unidos e de França, é significativa a presença de contratos simultâneos entre esses trabalhadores como forma de se evitar as ameaças de desemprego ou os baixos rendimentos no setor.

Alper e Wassall (2006) estudam o mercado de trabalho artístico norte-americano e australiano através de dados em pseudopainel obtidos de vários censos para examinar quais variáveis influenciam a empregabilidade e os rendimentos do mercado de trabalho artístico. Os resultados mostram que os artistas trabalham menos horas, encontram-se desempregados com maior frequência, têm maior variabilidade em relação aos rendimentos e ganham menos do que os outros trabalhadores com níveis equiparáveis de educação e treinamento.

Alguns estudos também têm empregado modelos de equações de rendimentos para o setor, com base na perspectiva da teoria do capital humano e a abordagem de Mincer (1958). O trabalho de Towse (2006), por exemplo, busca relacionar a teoria do capital humano e o mercado de trabalho artístico. Contudo, para a autora, tal teoria aplica-se fracamente às decisões dos artistas a respeito da qualificação para o trabalho e quanto à escolha da profissão. Há alguns aspectos do trabalho artístico, como talento e outras habilidades inatas ao trabalhador, os quais não são inteiramente compreendidos pela teoria do capital humano tradicional.

O trabalho de Filer (1990), utilizando microdados do censo norte-americano de 1980, encontra evidências de que o impacto da escolaridade na renda dos artistas é menor do que o observado para outros grupos profissionais comparados na análise. Filer percebe, ainda que, mesmo entre os artistas podem existir diferenças nos impactos dessa variável, que exerce menor força entre os apresentadores e locutores, atores e diretores, sendo mais importante para os autores. Adicionalmente, a análise conclui que a experiência pode ser uma das variáveis mais importantes para explicar os rendimentos do setor, pois captaria elementos não observáveis, como o talento dos indivíduos. Throsby (1994) também defende a importância do fator talento para explicar as remunerações recebidas no setor, afirmando que esse mercado tende a contrariar a teoria tradicional de formação da 
oferta de trabalho que postula a desutilidade dessa atividade. Além da utilidade obtida através dos rendimentos, o artista também extrai utilidade quando desempenha a atividade artística, sendo que, normalmente, esse tipo de trabalhador abre mão de ocupações que ofereçam melhor recompensa pecuniária para dedicar-se ao trabalho artístico. Dessa forma, o investimento em capital humano explicaria fracamente os rendimentos das atividades artísticas.

Para o Brasil, fontes com algum rigor econômico sobre esse mercado de trabalho ainda são escassas, ficando essa tarefa a cargo do escopo de outras ciências na maior parte dos casos. Segnini (2007), por exemplo, busca analisar as relações sociais observadas no mercado e nas relações de trabalho em arte, destacando a música e a dança. Ela se utiliza de um estudo comparativo entre Brasil e França, buscando delinear a divisão internacional do trabalho, o mercado de trabalho, condições de trabalho e relações de gênero, baseando-se nos dados da Classificação Brasileira de Ocupações (CBO) de 2002. A autora identifica ainda que a maioria dos profissionais dos espetáculos e das belas artes está desempenhando suas atividades através de contratos informais e que apenas $11,5 \%$ dos trabalhadores artistas mantêm relações formais de trabalho. Um dos motivos apontados é a forma como se organiza o mercado de espetáculos ao vivo, nos quais os trabalhadores são contratados de forma a se adequar à estrutura de custos de cada projeto. Assim, a constante reorganização dos fatores de produção impõe flexibilidade ao trabalhador artístico ou técnico do espetáculo.

Neto et al. (2012), através dos microdados disponibilizados pela PNAD (2002- 2007), buscam compreender os diferenciais entre os rendimentos dos trabalhadores inseridos na indústria cultural, separados entre artistas e não artistas, daqueles empregados em atividades não pertencentes ao setor cultural. Segundo os resultados, os trabalhadores brasileiros do setor cultural apresentam remuneração superior quando comparados aos demais setores cobertos pelos dados. Fatores como anos de estudo, experiência e idade impulsionam positivamente os rendimentos, além de se observar um efeito salarial positivo entre as mulheres do setor cultural. Já entre os dados que consideram apenas os artistas, há evidências de que esses trabalhadores são melhor remunerados que os trabalhadores agrupados em toda a indústria cultural. Além disso, a experiência implica maiores remunerações, enquanto o estudo está relacionado de maneira negativa com as remunerações para os artistas profissionais. 
Diniz (2008), utilizando microdados do censo demográfico de 2000, procura identificar algumas características do setor cultural brasileiro e estima equações de salários para os trabalhadores do setor. Através do uso de regressões quantílicas, a autora estima os efeitos de diversas variáveis sobre os rendimentos o setor cultural e encontra resultados que demonstram remunerações superiores para os artistas performáticos quando comparados a outras categorias. Há ainda indícios de que a educação produz efeitos crescentes sobre os salários à medida que se avança para partes superiores da distribuição de salários, bem como a experiência e a formalidade, além da existência de desigualdade nos salários devido às características de gênero e raça. $O$ estudo permite constatar que os retornos da educação são menores nos dois extremos das faixas de renda e que a formalidade exerce maior influência para a faixa menor da distribuição de rendimentos, decrescendo ao longo das outras categorizações de renda.

Machado et al. (2014) mostram com os dados da Pesquisa Mensal de Emprego (PME) e das finanças públicas municipais (Finanças do Brasil FINBRA) que o mercado de trabalho do setor cultural está caracterizado por uma jornada de trabalho com maior número de horas que os trabalhadores dos demais segmentos da economia no Brasil. Além disso, os autores encontram evidências de diferenciais de remuneração a favor de indivíduos homens e brancos, maior ganho nas atividades formalizadas e relação positiva entre os gastos públicos com atividades culturais e os ganhos dos trabalhadores do setor.

Em síntese, os artigos descritos apontam para uma elevada taxa de informalidade dos trabalhadores do setor artístico, ou cultural, e não há consenso sobre a efetividade da teoria do capital humano na explicação de seus rendimentos. A maior parte dos estudos analisa o comportamento médio dos trabalhadores e realiza comparações com as ocupações não artísticas. Os autores evidenciam também a existência de diferenciais de remuneração dentro de um mesmo setor, relacionados, entre outros fatores, ao tipo de ocupação do indivíduo. Nesse contexto, é possível pensar que os rendimentos não são determinados da mesma maneira entre os trabalhadores e que podem existir segmentos dentro desse mesmo setor. Para o presente estudo, propõe-se uma divisão do mercado de bens artísticos em dois segmentos, baseados na abordagem da cauda longa, ou seja, mercados de hits e mercados de nicho.

Faltam na literatura trabalhos que relacionem diretamente a aborda- 
gem de Anderson (2006) com o comportamento do mercado de trabalho e dos rendimentos. Existe, portanto, uma lacuna que pode ser explorada ao supor que em cada segmento da curva de produção e distribuição de conteúdo cultural os rendimentos são distintamente determinados. Como hipótese de trabalho, é possível admitir que artistas profissionais e outras ocupações técnicas diretamente relacionadas à produção musical encontram-se dispersos nos vários pontos formadores da curva que relaciona a popularidade e a procura por produtos culturais (Figura 1). Outro pressuposto é o fato de que a melhor remuneração dos trabalhadores está ligada à venda de seus produtos e, por isso, estes estão representados na cabeça da curva. Conforme o número de produtos vendidos diminui, também diminuem os rendimentos do trabalho de artistas e técnicos, que são, nesse caso, representados na cauda da curva.

Para captar como se comportam os determinantes da renda em diferentes níveis de rendimento do trabalho artístico, serão utilizadas regressões quantílicas. Cada quantil utilizado corresponderá a uma área específica da curva de cauda longa. Os quantis mais elevados farão referência à região da "cabeça" da curva. Além deste, há quantis para representação da área logo posterior à cabeça, em que se pressupõe estarem os trabalhadores de renda média e, por fim, os menores quantis, que remeterão à área abaixo da "cauda" da curva, representando os segmentos de nicho.

A próxima seção descreve o método utilizado para análise do problema proposto, apontando, ainda, a origem dos dados e as principais características das variáveis utilizadas nesta análise.

\section{Metodologia}

O trabalho utiliza como fonte de dados a Pesquisa Nacional por Amostra de Domicílios (PNAD), realizada anualmente pelo Instituto Brasileiro de Geografia e Estatística (IBGE), exceto em anos de censo demográfico, e que investiga características gerais da população brasileira, tais como níveis de educação, trabalho, rendimentos e características habitacionais. Entre a grande quantidade de dados disponibilizados pela PNAD, foram obtidas informações sobre a ocupação atual de cada indivíduo, na semana de referência das entrevistas, selecionando os atuantes em ocupações do setor produtor de conteúdo musical. 
O segmento profissional investigado constitui-se dos ocupados em atividades relacionadas direta e indiretamente à produção de conteúdo musical, seja através de fonogramas ou de performances ao vivo. Desconsideram-se, entretanto, as atividades que produzem materiais acessórios à produção musical, tais como a confecção de instrumentos musicais e outros insumos utilizados por essa atividade. O objetivo dessa diferenciação é compreender a dinâmica salarial do núcleo da atividade musical, sem levar em consideração panoramas de atividades acessórias. Para atender a essa finalidade, são utilizados os três grupos de ocupações listados no Quadro A1, deste artigo.

Adicionalmente, são filtradas informações válidas de indivíduos ocupados na semana de referência, com renda positiva, não militares, não funcionário público estatutário e não empregadores, com idade entre 18-65 anos e que contenham informações completas para todas as variáveis do modelo. O período considerado é o intervalo entre os anos de 2002-2014. O modelo a ser estimado é inspirado em Mincer (1974), buscando identificar os determinantes do rendimento-hora do trabalhador, levando em conta as variáveis de capital humano e outras variáveis não relativas à produtividade do trabalho que influenciam, de alguma maneira, a diferenciação observada na distribuição de rendimentos. $\bigcirc$ modelo a ser estimado é dado pela equação:

$$
\begin{aligned}
& \ln (r h)=\beta_{0}+\beta_{1} \text { Escolaridade }+\beta_{2} \text { Idade }+\beta_{3} \text { Idade }^{2}+\beta_{4} \text { Gênero }+ \\
& +\beta_{5} \text { Cor }+\beta_{6} \text { Chefe dom }+\beta_{7} \text { Região metrop. }+\beta_{8} \sum \text { Tipo de contrato }+ \\
& +\beta_{9} \sum \text { Setor }+\beta_{10} \sum \text { Ocupação }+\beta_{11} \sum \text { Região }+ \\
& +\beta_{12} \sum \text { Ano }+\beta_{13} \sum \text { Coorte }
\end{aligned}
$$

em que th é o logaritmo do rendimento por hora de trabalho; Escolaridade é a variável que mede os anos investidos em educação formal, variando entre 1 ano e 15, ou mais, anos de estudo; Idade é a idade calculada do indivíduo; Gênero é uma binária para o sexo do indivíduo; Cor se refere a uma dummy para diferenciação entre trabalhadores brancos e não brancos, sendo zero para estes últimos; Chefe dom. é uma dummy de valor 1 para a pessoa de referência da unidade familiar, e zero em caso contrário; Região metrop. tem valor 1 para trabalhadores residentes em áreas metropolitanas; Tipo de contrato é um conjunto de dummies para tipos de contratos de trabalho (com 
carteira; informal ${ }^{5}$; autoemprego); Setor define a agrupação dos trabalhadores em três setores de atividade (serviços coletivos; serviços gerais; outros ${ }^{6}$ ); Ocupação são dicotômicas que representam os três grupos de ocupação utilizados na análise, como uma tentativa de se controlar o efeito de potenciais profissionais que porventura possam atingir o status de superstar ${ }^{7}$ ou melhores potenciais de ganhos salariais; Região e Ano são, respectivamente, os conjuntos de dummies para as regiões do país e para os anos da amostra.

Finalmente, coorte é um conjunto de variáveis binárias que marcam a geração de nascimento dos indivíduos. Esses fatores foram incluídos para tentar controlar fatores não observáveis, mas que são típicos do trabalho cultural, como talento e aptidão (Neto et al.; 2012). As coortes foram definidas com um intervalo de 10 anos, totalizando 6 binárias. Os valores referentes aos rendimentos foram convertidos utilizando-se o deflator baseado em Corseuil e Foguel (2002), transformando os valores nominais em reais, referentes a janeiro de 2016. As estatísticas descritivas de cada variável são descritas na Tabela 1.

Tabela 1 Estatísticas descritivas das variáveis utilizadas no modelo

\begin{tabular}{lrr|r|r|r|r}
\hline Variável & $\begin{array}{r}\mathbf{N}^{0} \text { de } \\
\text { observações }\end{array}$ & Média & $\begin{array}{r}\text { Desvio } \\
\text { padrão }\end{array}$ & Mínimo & Máximo \\
\hline Salário-hora & 3.626 & 23,79 & 49,02 & 0,29 & $1.223,65$ \\
\hline Estudo & 3.626 & 9,81 & 3,26 & 0 & 15 \\
\hline Idade & 3.626 & 33,75 & 11,15 & 18 & 65 \\
\hline
\end{tabular}

Distribuição ao longo da cauda (quantis)

\begin{tabular}{|c|c|c|c|c|c|}
\hline & 0,10 & 0,25 & 0,50 & 0,75 & 0,90 \\
\hline & Nichos & Nichos & Mediana & Hits & Hits \\
\hline Salário-hora & 2,89 & 5,58 & 13,82 & 34,41 & 106,67 \\
\hline Estudo & 8,71 & 8,96 & 9,87 & 10,51 & 10,87 \\
\hline \multirow[t]{2}{*}{ Idade } & 29,01 & 31,39 & 33,88 & 36,67 & 37,06 \\
\hline & & & & & ntinua) \\
\hline \multicolumn{6}{|c|}{5 Trabalhadores assalariados sem a carteira de trabalho. } \\
\hline \multicolumn{6}{|c|}{$\begin{array}{l}6 \text { Dado que o setor cultural está essencialmente concentrado em atividades de prestação de } \\
\text { serviços, foi feita uma classificação arbitrária em apenas três grupos. }\end{array}$} \\
\hline \multicolumn{6}{|c|}{$\begin{array}{l}7 \text { Superstars são indivíduos que dominam as atividades nas quais estão inseridos e delas ob- } \\
\text { têm grandes quantidades de dinheiro. O talento dessas pessoas é reconhecido sobremaneira } \\
\text { ao talento de seus pares, provocando diferenciações de rendimentos (Rosen, } 1981 \text { apud Tow- } \\
\text { se, 2006). Obviamente, nem todas as ocupações ou profissões possuem potencial para que } \\
\text { seus trabalhadores atinjam o status de superstars. Para o caso específico dos dados empregados } \\
\text { da PNAD no presente trabalho, contudo, não é possível separar com perfeição esses casos, } \\
\text { uma vez que são utilizados apenas três grupos de ocupações, como mostra o Quadro A1. }\end{array}$} \\
\hline
\end{tabular}


Tabela 1 (continuação)

\begin{tabular}{lrrr}
\hline Variáveis binárias & & \\
\hline Variável & N $^{0}$ de observações & $\%$ \\
\hline Homens & 3.626 & 14,75 \\
\hline Brancos & 3.626 & 49,94 \\
\hline Chefes de domicílio & 3.626 & 48,12 \\
\hline Região metropolitana & 3.626 & 42,86 \\
\hline Formal & 3.626 & 19,36 \\
\hline Informal & 3.626 & 29,65 \\
\hline Autoemprego & 3.626 & 50,99 \\
\hline Serviços coletivos & 3.626 & 90,95 \\
\hline Serviços gerais & 3.626 & 6,59 \\
\hline Outros setores & 3.626 & 2,45 \\
\hline Ocupação 1 & 3.626 & 28,4 \\
\hline Ocupação 2 & 3.626 & 9,7 \\
\hline Ocupação 3 & 3.626 & 61,9 \\
\hline Norte & 3.626 & 13,02 \\
\hline Nordeste & 3.626 & 33,29 \\
\hline Sudeste & 3.626 & 27,61 \\
\hline Sul & 3.626 & 15,03 \\
\hline Centro-Oeste & 3.626 & 11,06 \\
\hline & &
\end{tabular}

Fonte: Elaboração própria com base nos dados da PNAD.

Para captar o comportamento dos determinantes do salário-hora ao longo da curva que relaciona a popularidade e a quantidade de bens vendidos, ou seja, o gráfico que representa a abordagem da cauda longa, é utilizado o método de regressões quantílicas. O pressuposto é o de que os agentes que atuam no mercado definido pelas características da "cabeça" da curva, o mercado de hits, são aqueles que obtêm maiores salários. Já aqueles que atuam sob a área da "cauda" da curva, ou seja, o mercado de nichos, são compreendidos como indivíduos que possuem os menores rendimentos.

A utilização econométrica de regressões quantílicas inicia-se com o trabalho de Koenker e Basset (1978). O objetivo desse método econométrico é mensurar o efeito das variáveis explicativas em diferentes pontos da distribuição da variável dependente. Além disso, de acordo com Deaton (1995), esse método é de grande utilidade quando dados são reconhecidamente sujeitos à heterocedasticidade, como no caso da distribuição de ren- 
dimentos. Comparando com o método dos mínimos quadrados ordinários (MOO), as estimativas resultantes do emprego de regressões quantílicas se mostram mais eficientes nos casos de não normalidade dos erros, promovendo resultados mais robustos.

Os principais quantis utilizados serão o $1^{\circ}, 10^{\circ}, 25^{\circ}, 50^{\circ}, 75^{\circ}, 90^{\circ}$ e $99^{\circ}$, que terão seus resultados exibidos no corpo do artigo. Por hipótese de trabalho, os três primeiros captam os resultados para aqueles profissionais $1 \%, 10 \%$ e $25 \%$, respectivamente, mais pobres, ou seja, que possuem menores rendimentos pelo trabalho, medido pelo salário-hora. Em relação ao posicionamento desses trabalhadores na curva descrita pela cauda longa, entende-se que esses agentes atuam sob a área da "cauda" da curva, ou seja, mercados de nicho, já que experimentam menores retornos da venda do produto de seu trabalho. $\mathrm{O}$ quantil $50^{\circ}$ apresenta os resultados para a mediana da distribuição de rendimentos, espelhando a situação média do mercado de trabalho da indústria produtora de conteúdo musical. Já os três últimos quantis apresentam os resultados para as camadas $25 \%, 10 \%$ e $1 \%$ mais ricas, ou seja, trabalhadores que recebem maiores salários-hora. Desse ponto em diante, são encarados como atuantes na área sob a cabeça da curva descrita por Anderson (2006), ou seja, no mercado de hits. Além disso, são apresentados gráficos para variáveis selecionadas com os coeficientes ao longo de todos os quantis da distribuição de salário-hora.

Adicionalmente, para controlar possíveis problemas de viés de seleção, por não se considerar na amostra aqueles que se encontram desempregados, é adotada uma adaptação do procedimento de Heckman (1979) para o caso das regressões quantílicas (Buchinsky, 2001). Para tanto, foi aplicado o mesmo procedimento utilizado por Neto et al. (2012), empregando como equação de seleção um modelo binário de probabilidade 8 para a participação no mercado de trabalho dos indivíduos, tendo como explicativas uma binária para identificar a condição de chefe do domicílio, a condição de cônjuge, a condição de filho e a existência de criança de 0 a 5 anos no domicílio. Essa equação é usada para se extrair o termo de correção e incorporá-lo ao modelo principal de salário-hora. $O$ resultado da equação de seleção está disponível na Tabela B1.

As regressões quantílicas foram estimadas através do software estatístico Stata 11. A matriz de variância de cada modelo foi estimada pelo método 
de bootstrap, aprimorando o controle sobre os efeitos da heterocedasticidade. Na próxima seção são apresentados os modelos estimados e a discussão dos resultados.

\section{Resultados do modelo}

Os resultados podem ser observados na Tabela 2, com cada coluna representando um dos quantis estimados. Os três primeiros quantis captam o comportamento dos mercados de nicho, com as menores remunerações, enquanto a comercialização de hits é representada pelos três últimos quantis. Adicionalmente, os gráficos da Figura 2 mostram os coeficientes estimados para algumas variáveis selecionadas ao longo de vários quantis, comparando com as estimativas realizadas via mínimos quadrados ordinários (MQO) e apresentando os respectivos intervalos de confiança a 90\%. Apesar dos baixos valores de ajuste apresentados pelos Pseudo $\mathrm{R}^{2}$, os modelos são coerentes com as demais análises empíricas para esse recorte do mercado de trabalho ${ }^{9}$ e apresentam coeficientes com sinais esperados pelos modelos de equações salariais.

Tabela 2 Resultados do modelo de regressões quantílicas

\begin{tabular}{|c|c|c|c|c|c|c|c|}
\hline & (1) & (2) & (3) & (4) & (5) & (6) & (7) \\
\hline & Nichos & Nichos & Nichos & Mediana & Hits & Hits & Hits \\
\hline & 0,01 & 0,10 & 0,25 & 0,50 & 0,75 & 0,90 & 0,99 \\
\hline \multirow[t]{2}{*}{ Escolaridade } & ${ }^{*} 0,062$ & ${ }^{*} 0,043$ & ${ }^{*} 0,062$ & ${ }^{*} 0,070$ & ${ }^{*} 0,064$ & ${ }^{*} 0,049$ & 0,030 \\
\hline & $(0,02)$ & $(0,01)$ & $(0,01)$ & $(0,01)$ & $(0,01)$ & $(0,01)$ & $(0,02)$ \\
\hline \multirow[t]{2}{*}{ Idade } & ${ }^{* *} 0,095$ & ${ }^{*} 0,052$ & ${ }^{*} 0,051$ & ${ }^{*} 0,057$ & ${ }^{*} 0,054$ & $* * * 0,052$ & $-0,073$ \\
\hline & $(0,04)$ & $(0,02)$ & $(0,02)$ & $(0,01)$ & $(0,02)$ & $(0,03)$ & $(0,10)$ \\
\hline \multirow[t]{2}{*}{ Idade $^{2}$} & $*^{* *}-0,001$ & $* * *-0,000$ & * $-0,001$ & $*_{-}-0,001$ & $*-0,001$ & $* * *-0,001$ & 0,001 \\
\hline & $(0,00)$ & $(0,00)$ & $(0,00)$ & $(0,00)$ & $(0,00)$ & $(0,00)$ & $(0,00)$ \\
\hline \multirow[t]{2}{*}{ Gênero } & 0,029 & 0,065 & $-0,051$ & 0,003 & 0,027 & 0,165 & 0,148 \\
\hline & $(0,16)$ & $(0,06)$ & $(0,05)$ & $(0,06)$ & $(0,07)$ & $(0,10)$ & $(0,24)$ \\
\hline \multirow[t]{2}{*}{ Cor } & 0,100 & ${ }^{*} 0,149$ & ${ }^{*} 0,104$ & $* * * 0,064$ & 0,049 & 0,075 & 0,111 \\
\hline & $(0,11)$ & $(0,06)$ & $(0,03)$ & $(0,03)$ & $(0,05)$ & $(0,07)$ & $(0,17)$ \\
\hline \multirow[t]{2}{*}{ Chefe dom. } & ${ }^{*} 0,619$ & ${ }^{*} 0,344$ & ${ }^{*} 0,249$ & ${ }^{*} 0,175$ & $* * * 0,191$ & $* * * 0,232$ & $* * * 0,562$ \\
\hline & $(0,13)$ & $(0,08)$ & $(0,08)$ & $(0,06)$ & $(0,10)$ & $(0,12)$ & $(0,32)$ \\
\hline
\end{tabular}

9 Towse (2006) e Diniz (2008). 
Tabela 2 (continuação)

\begin{tabular}{|c|c|c|c|c|c|c|c|}
\hline & (1) & (2) & (3) & (4) & (5) & (6) & (7) \\
\hline & Nichos & Nichos & Nichos & Mediana & Hits & Hits & Hits \\
\hline \multirow[t]{2}{*}{ Região metrop. } & ${ }^{* *} 0,175$ & ${ }^{* *} 0,090$ & ${ }^{*} 0,102$ & ${ }^{*} 0,135$ & ${ }^{*} 0,266$ & ${ }^{*} 0,320$ & ${ }^{* *} 0,374$ \\
\hline & $(0,08)$ & $(0,04)$ & $(0,04)$ & $(0,04)$ & $(0,05)$ & $(0,05)$ & $(0,19)$ \\
\hline \multirow[t]{2}{*}{ Informal } & $*-0,357$ & $*-0,236$ & $*-0,122$ & $* * *-0,088$ & 0,070 & $* * * 0,145$ & 0,228 \\
\hline & $(0,10)$ & $(0,06)$ & $(0,04)$ & $(0,05)$ & $(0,05)$ & $(0,09)$ & $(0,26)$ \\
\hline \multirow[t]{2}{*}{ Autoemprego } & $*-0,422$ & ${ }^{* *}-0,142$ & 0,086 & 0,060 & ${ }^{*} 0,244$ & ${ }^{*} 0,319$ & 0,317 \\
\hline & $(0,10)$ & $(0,06)$ & $(0,06)$ & $(0,08)$ & $(0,06)$ & $(0,07)$ & $(0,25)$ \\
\hline \multirow[t]{2}{*}{ Serviços } & 0,068 & $-0,077$ & $-0,059$ & $*^{* *}-0,148$ & $* * *-0,116$ & ${ }^{* *}-0,232$ & $-0,096$ \\
\hline & $(0,12)$ & $(0,07)$ & $(0,08)$ & $(0,07)$ & $(0,06)$ & $(0,10)$ & $(0,39)$ \\
\hline \multirow[t]{2}{*}{ Outros setores } & $-0,256$ & $-0,161$ & $*-0,318$ & $*-0,308$ & $*-0,314$ & $-0,348$ & 0,755 \\
\hline & $(0,20)$ & $(0,13)$ & $(0,07)$ & $(0,07)$ & $(0,12)$ & $(0,24)$ & $(0,76)$ \\
\hline \multirow[t]{2}{*}{ Ocupação 2} & ${ }^{* *} 0,439$ & ${ }^{*} 0,406$ & ${ }^{*} 0,364$ & $* 0,510$ & ${ }^{*} 0,605$ & ${ }^{*} 0,531$ & 0,251 \\
\hline & $(0,20)$ & $(0,11)$ & $(0,08)$ & $(0,08)$ & $(0,09)$ & $(0,13)$ & $(0,27)$ \\
\hline \multirow[t]{2}{*}{ 0cupação 3} & $* * 0,359$ & ${ }^{*} 0,310$ & ${ }^{*} 0,256$ & ${ }^{*} 0,424$ & ${ }^{*} 0,424$ & ${ }^{*} 0,330$ & 0,114 \\
\hline & $(0,16)$ & $(0,06)$ & $(0,04)$ & $(0,04)$ & $(0,05)$ & $(0,10)$ & $(0,26)$ \\
\hline \multirow[t]{2}{*}{ Norte } & $-0,144$ & $-0,035$ & $-0,066$ & $-0,057$ & $-0,006$ & 0,001 & 0,093 \\
\hline & $(0,17)$ & $(0,07)$ & $(0,08)$ & $(0,05)$ & $(0,06)$ & $(0,13)$ & $(0,27)$ \\
\hline \multirow[t]{2}{*}{ Nordeste } & $*-0,508$ & $*-0,282$ & ${ }^{*}-0,296$ & $*-0,276$ & ${ }^{*}-0,247$ & $*^{*}-0,265$ & $* * *-0,590$ \\
\hline & $(0,14)$ & $(0,07)$ & $(0,07)$ & $(0,06)$ & $(0,05)$ & $(0,09)$ & $(0,24)$ \\
\hline \multirow[t]{2}{*}{ Sul } & $* * *-0,455$ & $-0,014$ & 0,004 & 0,026 & 0,054 & 0,061 & $-0,161$ \\
\hline & $(0,23)$ & $(0,09)$ & $(0,06)$ & $(0,07)$ & $(0,07)$ & $(0,08)$ & $(0,24)$ \\
\hline \multirow[t]{2}{*}{ Centro-0este } & 0,020 & 0,089 & 0,105 & 0,002 & 0,117 & 0,069 & $-0,180$ \\
\hline & $(0,16)$ & $(0,10)$ & $(0,07)$ & $(0,07)$ & $(0,08)$ & $(0,13)$ & $(0,22)$ \\
\hline \multirow[t]{2}{*}{2003} & 0,050 & ${ }^{* *}-0,196$ & $-0,127$ & $* * 0,239$ & $*-0,502$ & $* * *-0,310$ & 0,073 \\
\hline & $(0,21)$ & $(0,09)$ & $(0,08)$ & $(0,10)$ & $(0,09)$ & $(0,18)$ & $(0,23)$ \\
\hline \multirow[t]{2}{*}{2004} & $-0,076$ & $* * *-0,203$ & $-0,023$ & $-0,057$ & ${ }^{* *}-0,269$ & $-0,251$ & 0,445 \\
\hline & $(0,27)$ & $(0,10)$ & $(0,10)$ & $(0,11)$ & $(0,12)$ & $(0,17)$ & $(0,38)$ \\
\hline \multirow[t]{2}{*}{2005} & 0,224 & $-0,108$ & 0,039 & 0,003 & $-0,128$ & $-0,175$ & $-0,077$ \\
\hline & $(0,23)$ & $(0,10)$ & $(0,10)$ & $(0,10)$ & $(0,09)$ & $(0,20)$ & $(0,22)$ \\
\hline \multirow[t]{2}{*}{2006} & 0,046 & $-0,050$ & 0,049 & $-0,037$ & $* * *-0,232$ & $-0,293$ & $-0,150$ \\
\hline & $(0,27)$ & $(0,13)$ & $(0,09)$ & $(0,12)$ & $(0,12)$ & $(0,21)$ & $(0,33)$ \\
\hline \multirow[t]{2}{*}{2007} & 0,185 & 0,061 & 0,046 & 0,025 & $-0,074$ & 0,050 & 0,133 \\
\hline & $(0,31)$ & $(0,09)$ & $(0,09)$ & $(0,12)$ & $(0,11)$ & $(0,18)$ & $(0,28)$ \\
\hline
\end{tabular}


Tabela 2 (continuação)

\begin{tabular}{|c|c|c|c|c|c|c|c|}
\hline & (1) & (2) & (3) & (4) & (5) & (6) & (7) \\
\hline & Nichos & Nichos & Nichos & Mediana & Hits & Hits & Hits \\
\hline \multirow[t]{2}{*}{2008} & 0,214 & 0,068 & 0,042 & 0,106 & $-0,047$ & $-0,053$ & 0,308 \\
\hline & $(0,20)$ & $(0,10)$ & $(0,09)$ & $(0,09)$ & $(0,09)$ & $(0,17)$ & $(0,43)$ \\
\hline \multirow[t]{2}{*}{2009} & 0,524 & 0,054 & $* * * 0,135$ & 0,106 & $-0,129$ & $-0,153$ & $-0,007$ \\
\hline & $(0,43)$ & $(0,10)$ & $(0,08)$ & $(0,07)$ & $(0,11)$ & $(0,19)$ & $(0,37)$ \\
\hline \multirow[t]{2}{*}{2010} & $* * * 0,512$ & $-0,026$ & 0,082 & 0,195 & $-0,002$ & 0,073 & $* * 1,059$ \\
\hline & $(0,28)$ & $(0,16)$ & $(0,12)$ & $(0,12)$ & $(0,12)$ & $(0,22)$ & $(0,51)$ \\
\hline \multirow[t]{2}{*}{2011} & $* * * 0,385$ & 0,102 & 0,141 & 0,092 & 0,062 & 0,051 & 0,219 \\
\hline & $(0,23)$ & $(0,13)$ & $(0,12)$ & $(0,12)$ & $(0,14)$ & $(0,23)$ & $(0,65)$ \\
\hline \multirow[t]{2}{*}{2013} & ${ }^{* *} 0,525$ & 0,055 & 0,235 & $* * 0,238$ & 0,039 & $-0,013$ & 0,261 \\
\hline & $(0,23)$ & $(0,13)$ & $(0,16)$ & $(0,11)$ & $(0,14)$ & $(0,24)$ & $(0,39)$ \\
\hline \multirow[t]{2}{*}{2014} & ${ }^{*} 0,747$ & 0,066 & 0,162 & 0,187 & 0,121 & 0,221 & 0,338 \\
\hline & $(0,28)$ & $(0,14)$ & $(0,14)$ & $(0,12)$ & $(0,17)$ & $(0,27)$ & $(0,59)$ \\
\hline \multirow[t]{2}{*}{ Coorte 1950-59 } & $* *-0,652$ & $-0,115$ & $-0,061$ & $-0,155$ & $*-0,581$ & $* * *-0,506$ & 0,362 \\
\hline & $(0,25)$ & $(0,19)$ & $(0,18)$ & $(0,17)$ & $(0,19)$ & $(0,29)$ & $(0,84)$ \\
\hline \multirow[t]{2}{*}{ Coorte 1960-69 } & ** $-0,974$ & 0,214 & $-0,125$ & $-0,261$ & $*-0,788$ & $* *-0,764$ & 0,322 \\
\hline & $(0,42)$ & $(0,27)$ & $(0,19)$ & $(0,17)$ & $(0,23)$ & $(0,38)$ & $(1,11)$ \\
\hline \multirow[t]{2}{*}{ Coorte 1970-79 } & $* * *-0,979$ & 0,360 & $-0,111$ & $-0,301$ & *-0,897 & $* *-0,836$ & 0,814 \\
\hline & $(0,52)$ & $(0,38)$ & $(0,22)$ & $(0,21)$ & $(0,26)$ & $(0,39)$ & $(1,23)$ \\
\hline \multirow[t]{2}{*}{ Coorte 1980-89 } & $* * *-1,074$ & 0,470 & $-0,129$ & $-0,368$ & $*-1,064$ & $*^{* *}-0,891$ & 0,780 \\
\hline & $(0,59)$ & $(0,45)$ & $(0,27)$ & $(0,25)$ & $(0,30)$ & $(0,41)$ & $(1,38)$ \\
\hline \multirow[t]{2}{*}{ Coorte 1990-96 } & $-0,851$ & 0,720 & $-0,011$ & $-0,246$ & $*-0,890$ & $-0,632$ & 1,022 \\
\hline & $(0,67)$ & $(0,50)$ & $(0,33)$ & $(0,33)$ & $(0,33)$ & $(0,47)$ & $(1,40)$ \\
\hline \multirow[t]{2}{*}{ Mills } & $* *-4,467$ & $-0,841$ & $-0,256$ & 0,392 & $-0,094$ & $-0,743$ & $-1,754$ \\
\hline & $(1,74)$ & $(1,17)$ & $(0,79)$ & $(0,70)$ & $(0,93)$ & $(1,27)$ & $(2,58)$ \\
\hline \multirow[t]{2}{*}{ Mills2 } & $*-3,760$ & $-0,790$ & $-0,321$ & 0,136 & $-0,146$ & $-0,630$ & $-1,429$ \\
\hline & $(1,24)$ & $(0,84)$ & $(0,58)$ & $(0,50)$ & $(0,73)$ & $(0,96)$ & $(1,98)$ \\
\hline \multirow[t]{2}{*}{ Constante } & $-1,175$ & $-0,476$ & 0,423 & ${ }^{*} 1,278$ & $* 2,418$ & $* 2,663$ & 3,577 \\
\hline & $(1,19)$ & $(0,95)$ & $(0,53)$ & $(0,49)$ & $(0,53)$ & $(0,47)$ & $(2,35)$ \\
\hline Pseudo R2 & 0,1878 & 0,1329 & 0,1269 & 0,1275 & 0,1194 & 0,1058 & 0,1491 \\
\hline N. de obs. & 3626 & 3626 & 3626 & 3626 & 3626 & 3626 & 3626 \\
\hline
\end{tabular}

Fonte: Elaboração própria com base nos dados da PNAD.

Erros-padrão entre parênteses. ${ }^{*} p<0.10,{ }^{* *} p<0.05,{ }^{* * *} p<0.01$. 
De modo geral, observando o comportamento das variáveis idade e anos de estudo, os resultados apontam para confirmação do que é informado por muitos trabalhos empíricos, com uma influência positiva e significativa sobre o salário-hora do trabalhador do setor produtor de conteúdo musical. Esse comportamento se repete para toda a distribuição de salário-hora, como permitem observar os gráficos da Figura 2, apesar de não existir diferenças significativas entre os coeficientes estimados com um modelo de $\mathrm{MOO}$ na maior parte dos quantis estimados. A exceção parece ser o resultado não significativo para a idade, proxy de experiência, no quantil mais elevado, ou seja, entre os trabalhadores envolvidos na produção e comercialização de hits. Para esses trabalhadores, provavelmente os aspectos de capital humano mais relevantes não são os relacionados diretamente com a experiência de idade, mas com os de outras características, como habilidades inatas ou aptidão profissional. Entre os demais trabalhadores, os fatores de educação e experiência continuam a prevalecer como no mercado de trabalho tradicional.

Com relação às características pessoais, ao contrário do tradicionalmente observado tanto no mercado de trabalho como um todo quanto também em setores específicos da economia brasileira (BARROS; MENDONÇA, 1995), não foram encontrados coeficientes significativos para a binária de gênero em nenhum dos quantis estimados. Esse resultado mostra baixa discriminação salarial por razões de gênero entre os trabalhadores da indústria de bens artísticos no país.

Por outro lado, os resultados do modelo econométrico indicam a presença de discriminação por cor da pele no mercado de trabalho dos agentes produtores de conteúdo musical, em algumas das faixas de renda estudadas. De acordo com os resultados, a discriminação por cor influencia mais na determinação dos salários do que os fatores relacionados ao gênero ao qual pertence o trabalhador. Assim, para os trabalhadores situados sob a "cabeça" da curva descrita pela cauda longa, ou seja, no mercado dos hits, os fatores discriminatórios citados exercem menor influência do que pode ser observado para aqueles indivíduos sob a "cauda" da curva. Esse resultado sugere que no mercado de hits o efeito superstar sobrepõe barreiras relacionadas à cor do indivíduo. Esse efeito, segundo Adler (2006), ocorre quando indivíduos atingem consideráveis níveis de sucesso em um campo de atuação definido, tal como nas artes ou esportes, e, como resultado, são remunerados de maneira extraordinária. 
Figura 2 Coeficientes estimados para variáveis selecionadas
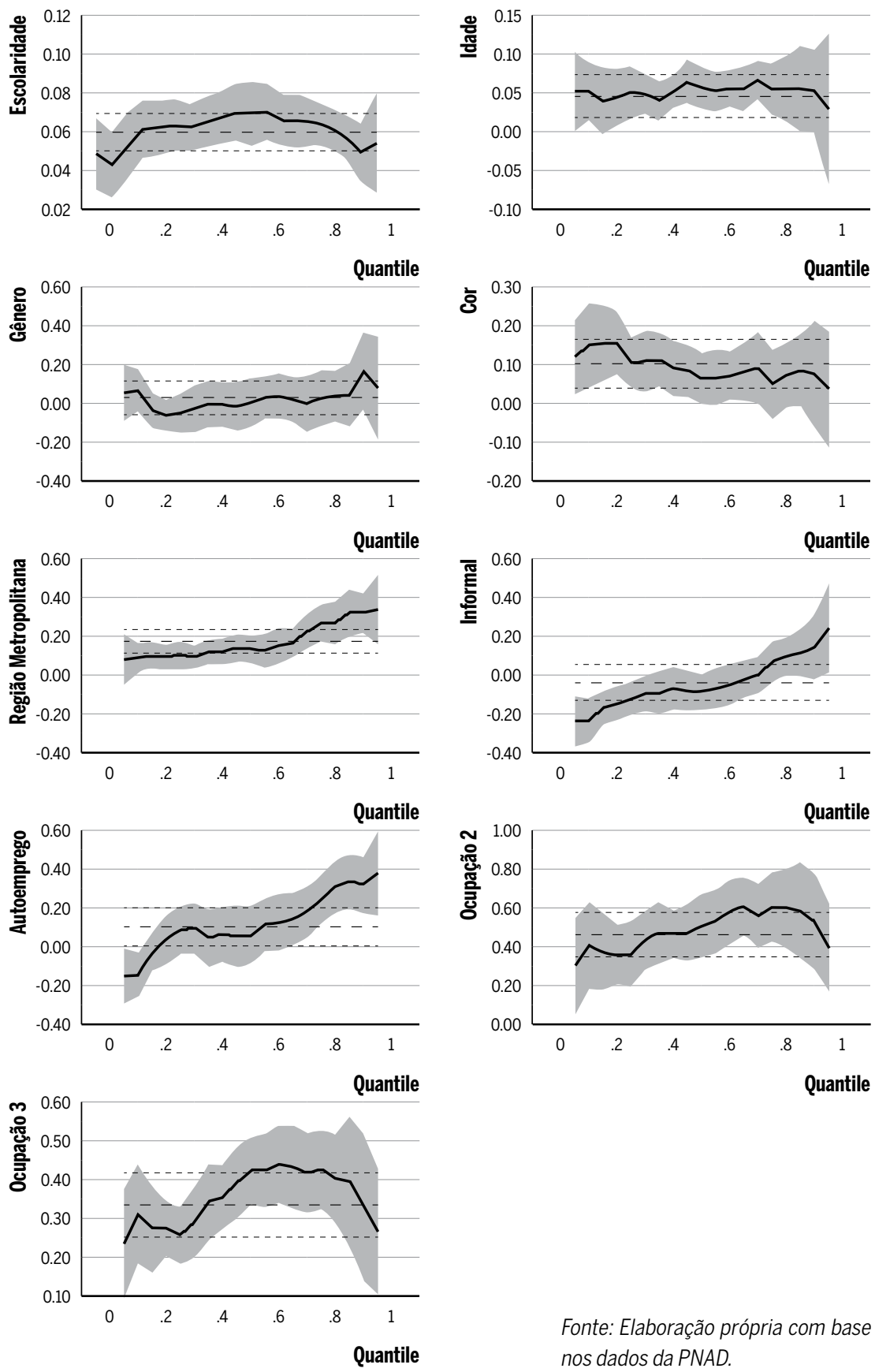

Fonte: Elaboração própria com base nos dados da PNAD. 
Dessa forma, para os trabalhadores da produção de conteúdo musical no topo da distribuição de renda, características de cor ou gênero já não seriam relevantes em virtude do sucesso atingido, passando a ser mais intensa a participação de fatores relacionados ao talento ou posse de outros fatores produtivos. Em geral, análise dos diferencias salariais entre grupos pode ser decomposta em efeitos relacionados com a discriminação (cor, gênero etc.), e fatores causados por diferenças na posse de características produtivas, usando ferramentas como a proposta por Oaxaca (1973), por exemplo. A partir da adaptação de Melly (2005), é possível realizar essa decomposição considerando cada quantil da distribuição de salário-hora, ou seja, tomando como base uma série de modelos de regressão quantílica ${ }^{10}$. Com base nesse método, foi decomposta a diferença entre brancos e não brancos, tomando a distribuição salarial dos primeiros como referência, para cada uma série de quantis, como mostram os resultados expostos na Figura 3. Como é possível constatar, à medida que se avança para os quantis que representam os trabalhadores mais relacionados com a comercialização de hits, uma redução do componente de discriminação e aumento no papel das características observáveis, principalmente a partir do $90^{\circ}$ quantil, onde o efeito da discriminação perde significância estatística. Isso parece reforçar a hipótese do efeito superstar, uma vez que para os trabalhadores da indústria de hits o que parece prevalecer é a posse de características produtivas para explicar a diferença entre brancos e não brancos.

Figura 3 Decomposição do diferencial de salário-hora entre brancos e não brancos ao longo dos quantis
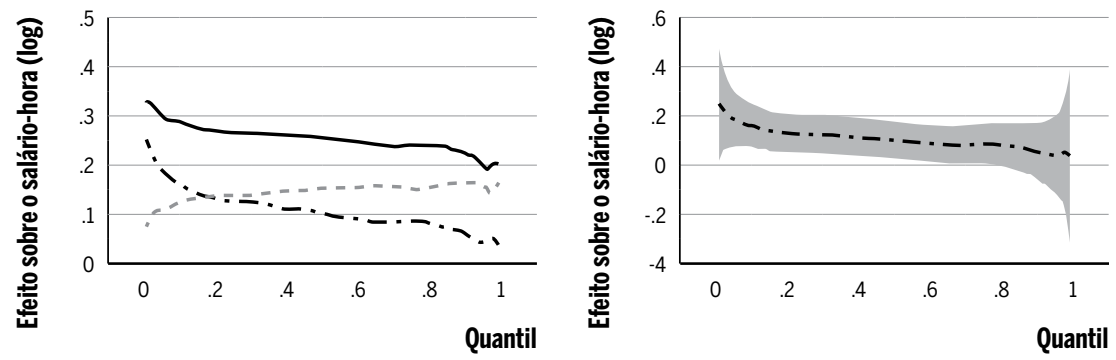

Diferencial total -..-.- Coeficientes

Características observáveis

Fonte: Elaboração própria com base nos dados da PNAD.

10 Foi utilizado o comando rqdeco para Stata. São estimadas regressões condicionadas a cada quantil para brancos e não brancos, baseando-se nas mesmas variáveis dos modelos principais, sendo, então, realizada a decomposição. 
Por outro lado, esse efeito superstar pode também esconder o papel de características não observáveis entre os trabalhadores do setor cultural, principalmente quando se considera que nem todas as categorias de ocupação consideradas têm real potencial para chegar tão longe na carreira de sucesso. Contudo, a classificação da CBO disponível na PNAD utilizada neste trabalho de pesquisa não permite maior detalhamento destas.

O fato de o trabalhador residir, ou não, em regiões metropolitanas é também determinante para a composição do rendimento por hora de trabalho. Para os produtores de conteúdo musical, viver em grandes aglomerados urbanos incrementa o salário, conforme aponta o trabalho de Menger (2006), uma vez que o consumo dos produtos dessa indústria ocorre de forma intensiva em aglomerados urbanos. Essa relação é crescente conforme são analisados os diferentes quantis. Assim, para os trabalhadores que se situam na cabeça da curva descrita por Anderson (2006), ou seja, os separados nos quantis $75^{\circ}, 90^{\circ}$ e $99^{\circ}$, morar em grandes cidades contribui de forma incisiva para o aumento dos rendimentos. Enquanto isso, para os trabalhadores que permanecem sob a cauda da curva, a importância de morar perto de grandes cidades para a composição dos salários é menor.

A maior importância dos centros urbanos para os trabalhadores situados sob a área da cabeça da curva pode ser entendida se considerado que os grandes centros consomem sobremaneira os produtos classificados como hits, e que ainda dependem, em grande parte, da distribuição através de suportes físicos pelas redes de varejo e grandes lojas especializadas. Esse seria o modelo de negócios que, segundo Anderson (2006), atua predominantemente no mercado identificado pela cabeça da curva descrita na Figura 1. As facilidades de distribuição e o modelo de consumo dos produtos originados daqueles trabalhadores que estão localizados sob a cauda da curva podem justificar a menor importância da variável "região metropolitana" para esses trabalhadores.

As duas últimas variáveis a serem analisadas no modelo de regressões quantílicas estimado neste trabalho tratam das condições dos contratos de trabalho dos produtores de conteúdo musical. São consideradas três modalidades de contratos, formais, informais e situações de autoemprego, sendo que a primeira situação é tomada como referência. Para o Brasil, postos de trabalho não registrados tendem a empregar pessoas menos qualificadas e a pagar menores salários do que aqueles regulamentados. Para o mercado de trabalho dos produtores de conteúdo musical, entretanto, esse 
resultado ocorre somente em alguns estratos de renda. Até a mediana, o fato de não manter vínculos formais de trabalho reduz o salário-hora dos trabalhadores. Por hipótese, esses são aqueles trabalhadores que se situam entre os profissionais que atuam em mercados de nicho.

A variável que indica a situação de empregabilidade por conta própria também apresenta efeitos crescentes. Desse modo, é possível concluir que os trabalhadores atuantes no mercado produtor de conteúdo musical, principalmente aqueles que se situam na "cabeça" do gráfico de cauda longa, representados por quantis superiores ao $75^{\circ}$, são beneficiados por maior mobilidade permitida por meio da inexistência de vínculos formais de trabalho, principalmente pela condição de autoemprego. Entretanto, para os trabalhadores mais pobres, situados sob a "cauda" da curva, a informalidade diminui os rendimentos por hora de trabalho, tal como ocorre no mercado de trabalho tradicional.

Esse aumento nos rendimentos dos artistas profissionais através da informalidade e do emprego por conta própria pode ser justificado com base na estrutura de contratação dessa indústria e na característica predominante de organização dos trabalhadores desse setor. Segundo Benhamou (2007), há predominância de contratos temporários e sazonais de trabalho. Isso decorre das características de custos dos projetos de produção de conteúdo cultural, que estimula a preferência por profissionais de reconhecida competência, extremamente especializados, elevando os custos relacionados aos salários, principalmente na região da "cabeça" da curva de cauda longa, descrita por Anderson (2006). Nesse mercado de hits é possível encontrar estruturas produtivas bem organizadas e com grande capacidade de gerenciamento de projetos que envolvam grandes volumes de investimento, e que, por isso, demandam mão de obra de maior competência, ou seja, artistas profissionais e técnicos que possuem boa reputação. Além disso, parte significativa dos rendimentos dos profissionais do mercado de produção de conteúdo musical é proveniente de apresentações ao vivo. Os contratos utilizados nesse tipo de produção são pontuais, não caracterizando vínculos empregatícios formais. Por fim, devido à inexistência de vínculos de trabalho, os profissionais podem atuar de maneira simultânea em várias atividades, maximizando seus rendimentos. $O$ mercado de trabalho artístico é permeado por várias formas flexíveis de autoemprego, tais como o freelancer, o emprego em tempo parcial, a acumulação de vários contratos de trabalho e a busca de cada 
trabalhador em inserir-se em vários projetos que possam lhe garantir algum fluxo de renda (Segnini, 2007).

Em síntese, os resultados evidenciam que a remuneração dos trabalhadores do mercado de nichos não é determinada da mesma maneira que entre os profissionais relacionados aos produtos denominados de hits, principalmente no que se refere ao impacto do tipo de contrato de trabalho estabelecido. Entre os primeiros, as relações formais e estáveis de trabalho se apresentam como mais importantes, ao passo que a mão de obra de hits parece se beneficiar da maior flexibilidade fornecida pela informalidade. Portanto, a informalidade se apresenta como estratégia de maiores ganhos salariais para os trabalhadores da "cabeça" da curva da cauda longa (Pianto; Pianto, 2002).

\section{Considerações finais}

Este trabalho objetiva analisar os determinantes dos salários dos produtores de conteúdo musical, diferenciando esses trabalhadores com base na abordagem da cauda longa, desenvolvida por Anderson (2006). Segundo o autor, o mercado musical pode ser dividido em dois, ou seja, o mercado de hits e os mercados de nicho. Estes últimos tornaram-se economicamente viáveis após os avanços observados em informática, bem como em tecnologia de informação. Pressupõe-se que os trabalhadores mais bem remunerados são atuantes nos mercados de hits, já que esse mercado movimenta grande quantidade de recursos na tentativa de viabilizar a venda de seus poucos produtos massificados. Já os trabalhadores menos remunerados devem atuar nos nichos, onde os investimentos são menores, uma vez que o tamanho de cada um desses mercados é, também, menor.

O uso de equações de rendimento com o método das regressões quantílicas mostra distintos impactos dos fatores sobre os rendimentos dos trabalhadores atuantes na parte da calda que representa os hits e os envolvidos nos mercados de nicho, direcionados a um público mais específico e segmentado. A binária de cor, por exemplo, revela maior discriminação a favor dos trabalhadores brancos entre os ocupados na cauda longa ou mercados segmentados. Nos quantis mais elevados, os efeitos de cor são menores, o que pode ser explicado pela condição descrita pela de teoria dos superstars, ou seja, o fato de os trabalhadores representados nos quantis mais elevados, atuantes no mercado de hits, gozarem de fama e reconhe- 
cimento minimiza a ação de fatores discriminatórios sobre os ganhos provenientes do trabalho. O uso de uma decomposição do tipo Oaxaca (1973) confirma esse resultado, mostrando uma não significância do componente discriminação entre os quantis superiores.

Um fato que chama a atenção é a inversão observada em relação ao papel dos tipos de contratos de trabalho utilizados no ambiente de produção de conteúdo musical. Enquanto a literatura sobre o mercado de trabalho brasileiro indica que profissionais que possuem contratos formais de trabalho obtêm maiores salários, no mercado produtor de conteúdo musical ocorre o contrário, em algumas situações. Nos quantis mais elevados, ou seja, na cabeça da curva de cauda longa, ou no mercado de hits, o fato de o trabalhador não ser formalmente contratado resulta no recebimento de melhores salários. Isso é observado com mais relevância para as situações de autoemprego, que apresenta um alto valor para o parâmetro que mede essa condição para os trabalhadores 10\% melhor remunerados, ou seja, o $90^{\circ}$ quantil. Dessa forma, não possuir vínculos empregatícios formais pode constituir-se uma estratégia para os trabalhadores desse setor, conforme sugere Pianto e Pianto (2002), já que essa flexibilidade entre os trabalhadores e empregadores se adéqua muito bem às características de sazonalidade e de intermitência do mercado produtor de conteúdo musical.

Conclui-se que os determinantes dos salários dos profissionais atuantes no mercado produtor de conteúdo musical não exercem a mesma influência entre os trabalhadores melhor remunerados, situados, por hipótese, na "cabeça" da curva descrita por Anderson (2006), ou seja, no mercado de hits, e os trabalhadores que experimentam menor remuneração pelo seu trabalho, atuantes nos mercados de nicho, localizado sob a "cauda" da curva que relaciona a procura pelos produtos musicais e sua popularidade.

Este estudo procura avançar na compreensão estrutural do mercado de trabalho dos produtores de conteúdo musical, na tentativa de compreendê-lo além das noções apreendidas do pronunciamento das entidades representantes das grandes empresas do setor fonográfico. Este exercício leva em consideração alguns aspectos relacionados aos avanços técnicos em informática e tecnologia da informação, que são apontados como os principais fatores reorganizadores dessa indústria. Entretanto, esses fatores são, geralmente, observados como viabilizadores de práticas que levaram a indústria fonográfica para uma situação de crise, ou seja, a redução das margens de lucros das grandes empresas. 
Num cenário em que as barreiras à entrada de novos produtores parecem diminuir, e numa indústria em que o produto pode ser extremamente diferenciado, como no caso da indústria musical, é importante compreender as questões relacionadas diretamente ao mercado de trabalho. Sendo assim, cabe salientar que há espaço para melhorias desta análise, por meio do aprofundamento da pesquisa iniciada por este artigo. $O$ estudo das diferenças entre as características intrassetoriais no mercado de trabalho artístico, bem como do papel do segundo emprego na composição da renda dos profissionais desse setor, constitui uma extensão ainda não explorada desse campo de pesquisa incipiente no Brasil. Outro apontamento para futuras pesquisas consiste na observação da evolução dos rendimentos agregados desses trabalhadores, tentando estabelecer alguma relação com os avanços em informática e tecnologia da informação.

\section{Referências}

ADORNO, T. W.; HORKHEIMER, M. Dialética do esclarecimento. Trad. de Guido Antônio de Almeida. Rio de Janeiro: Zahar, 1986.

ADLER, M. Stardom and talent. In: GINSBURG, A; THROSBY, D. (Ed.). Handbook of the Economics of Art and Culture. Amsterdã: North-Holland, 2006. p. 895-906.

ALPER, N. O.; WASSALL, G. H. Artists' Careers and their Labour Markets. In: GINSBURG, A; THROSBY, D. (Ed.). Handbook of the Economics of Art and Culture. Amsterdã: NorthHolland, 2006. p. 812-864.

ANDERSON, C. A cauda longa: do mercado de massa para o mercado de nicho. 5. ed. Trad. Afonso Celso da Cunha Serra. Rio de Janeiro: Elsevier, 2006.

ASSOCIAÇÃO BRASILEIRA DOS PRODUTORES DE DISCOS. Mercado brasileiro de música 2009. Disponível em: <http://www.abpd.org.br/downloads.asp>. Acesso em: 15 nov. 2012. 2010.

ASSOCIAÇÃO BRASILEIRA DOS PRODUTORES DE DISCOS. Mercado brasileiro de música 2015. Disponível em: <http://www.abpd.org.br/wp-content/uploads/2016/04/MERCADO_FONOGRAFICO_BRASILEIRO_E_MUNDIAL_2015_FINAL_PDFSITE.pdf $>$. Acesso em: 20 maio 2016.

BARROS, R. P.; MENDONÇA, R. S. P. Os determinantes da desigualdade no Brasil. Rio de Janeiro: IPEA, jul. 1995.

BENHAMOU, F. A economia da cultura. Trad. Geraldo Gerson de Souza. Cotia, SP: Ateliê Editorial, 2007.

BUCHINSKY, M. Quantile Regression with Sample Selection: Estimating Women's Return to Education in the U. S. Empirical Economics, n. 26, p. 87-113, 2001. 
CORSEUIL, C. H. E.; FOGUEL, M. N. Uma sugestão de deflatores para rendas obtidas a partir de algumas pesquisas domiciliares do IBGE. Texto para Discussão, 897. Rio de Janeiro: IPEA, 2002.

CORTÊS, M.; et al. A cauda longa e a mudança do modelo de negócio no mercado fonográfico: reflexões acerca do impacto das novas tecnologias. In: ENCONTRO NACIONAL DE ENGENHARIA DA PRODUÇÃO. Rio de Janeiro: ABEPRO, 2008.

DEATON, A. Data and Econometric Tolls for Development Analysis. In: BERHMAN, J., SRINIVASAN, T. N. (Ed.). Handbook of Development Economics. Amsterdã: Elsevier, 1995. v. 3a, p. $1.785-1.882$.

DINIZ, Sibelle C. Análise do setor cultural nas regiões metropolitanas brasileiras. In: $36^{\circ}$ ENCONTRO NACIONAL DE ECONOMIA, 2008, Salvador, BA. Anais...

ELBERSE, A. Should You Invest in the Long Tail? Harvard Business Review, v. 86, n. 7/8, p. 1-9, 2008.

FILER, R. Arts and Academe: The Effect of Education on Earnings of Artists. The Journal of Cultural Economics, v. 14, n. 2, p. 15-40, Dez. 1990.

HECKMAN, J. Sample Selection as a Specification Error. Econometrica, n. 47, p. 153-161, 1979.

IBGE. Pesquisa Nacional por Amostra de Domicílios. 2002-2014.

KOENKER, R.; BASSET, G. Regression Quantiles. Econometrica, v. 46, n. 1, p. 33-50, Jan. 1978.

MACHADO, A. F., RABELO, A.; MOREIRA, A. G. Specificities of the Artistic Cultural Labor Market in Brazilian Metropolitan Regions between 2002 and 2010. Journal of Cultural Economics, v. 38, n. 3, p. 237-251, 2014.

MELLY, B., Decomposition of Differences in Distribution Using Quantile Regression. Labour Economics, v. 12, n. 4, p. 577-590, 2005.

MENGER, P. Artistic Labour Markets: Contingent Work, Excess Supply and Occupational RiskManagement. In: GINSBURG, A; THROSBY, D. (Ed.). Handbook of the Economics of Art and Culture. Amsterdã: North-Holland, 2006. p. 765-811.

MINCER, J. Investment in Human Capital and Personal Income Distribuition. The Journal of Political Economics, v. 66, n. 4, p. 281-302, Ago. 1958. Disponível em: <http://www.jstor. org/stable/10.2307/1827422>. Acesso em: 22 Dez. 2012.

MINCER, J. Schooling, Experience and Earnings. National Bureau of Economic Research, Columbia University Press, 1974. Disponível em: <http://papers.nber.org/books/minc74-1>. Acesso em: 15 dez. 2012.

NAKANO, D. A produção independente e a desverticalização da cadeia produtiva da música. Gestão e Produção, São Carlos-SP, v. 17, n. 3, p. 627-638, 2010.

NETO, A. B. F.; FAJARDO, B. A.; FREGUGLIA, R. S. Diferenciais salariais para o setor cultural e ocupações artísticas no Brasil. Economia Aplicada, v. 16, n. 1, p. 49-76 2012.

OAXACA, R. L. Male - Female Differentials in Urban Labor Market. International Economic Review, Pensylvania, v. 14, n. 3, p. 693-709, 1973.

OESTREICHER-SINGER, G.; SUNDARARAJAN, A. Recommendation Networks and the Long Tail of Electronic Commerce. MIS Quarterly, v. 36, n. 1, p. 65-83, 2012.

PATOKOS, T. A New Era for the Music Industry: How New Technologies and the Internet 
Affect the Way Music is Valued and Have an Impact on Output Quality. Panoeconomicus, Atenas, v. 2, p. 233-248, 2008.

PIANTO, M. T; PIANT O, M. D. Informal Employment in Brazil: a Choice at the Top and Segmentation at the Bottom: a Quantile Regression Approach. Universidade de Brasília/ Universityof Illinois. 2002. Disponível em: <http://www.sbe.org,br/ede24/107. pdf.>. Acesso em: 15 nov. 2012.

POPOVIC, M.; RATKOVIC, K. Oversuply of Labor and Peculiarites of Arts Labor Market. Germany: Leibniz Information Centre for Economics, 2013. 29 p.

QUELCH, J. Long-tail economics? Give me Blockbusters! Disponível em: <http://hbswk.hbs. edu/item/6014.html>. Acesso em: 05 abr. 2008.

ROSEN, S. The Economics of Superstar. American Economic Review, v. 71, n. 5, p. 845-858, 1981.

RÜDIGER, F. A reflexão teórica em cibercultura e a atualidade da polêmica sobre a cultura de massas. Matrizes, v. 5, n. 1, p. 45-62, 2011.

STALLABRASS, J. Internet Art: The Online Clash of Culture and Commerce. London: Tate Pub. 2003.

SEGNINI, L.R.P. Criação rima com precarização: análise do mercado de trabalho artístico no Brasil. In: XIII CONGRESSO BRASILEIRO DE SOCIOLOGIA, 2007.

THROSBY, D.A Work-Preference Model of Artist Behaviour. In: PEACOCK, A.; RIZZO, I. Cultural Economics and Cultural Policies. Norwell (EUA), p. 69-801994.

TOLILA, P. Cultura e economia: problemas, hipóteses, pistas. Trad. Celso M. Pacionik. São Paulo; Iluminuras/Itaú Cultural, 2007.

TOWSE, R. Human Capital and Artists' Labour Markets. In: GINSBURG, A; THROSBY, D. (Ed.). Handbook of the Economics of Art and Culture. Amsterdam: North-Holland, 2006. p. 865-894.

ZUIN, A. Á. S. Sobre a atualidade do conceito de indústria cultural. Cadernos Cedes, v. 21, n. 54, p. 9-18, 2001.

YÚDICE, G. Economia da cultura no marco da proteção e promoção da diversidade cultural. Oficina Virtual de Economia da Cultura e Diversidade, jun. 2007.

\section{Sobre os autores}

Vinicius Barbosa Teixeira Machado dos Santos-vinibtms@gmail.com

Universidade Federal de Goiás, Goiânia, Goiás, Brasil.

ORCID: https://orcid.org/0000-0003-4350-7576.

SandroEduardoMonsueto-monsueto@ufg.br

(2) Universidade Federal de Goiás, Goiânia, Goiás, Brasil.

ORCID: https://orcid.org/0000-0002-2155-012X.

Bárbara Christina Pereira da Silva Carrijo - barbaracarrijo@outlook.com

Universidade Federal de Goiás, Goiânia, Goiás, Brasil.

ORCID: https://orcid.org/0000-0002-3245-6200.

\section{Sobre 0 artigo}

Recebido em 11 de novembro de 2015. Aprovado em 21 de junho de 2017. 


\section{APÊNDICE A}

\section{Quadro A1 Relação de códigos de ocupações consideradas}

\begin{tabular}{|c|c|}
\hline & Descrição das atividades \\
\hline \multirow{6}{*}{ 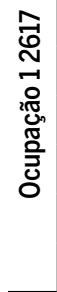 } & Comentarista de: esportes, jornal, rádio e televisão \\
\hline & Comentarista, narrador, locutor esportivo, \\
\hline & Comunicador, narrador, noticiarista, repórter de rádio e televisão \\
\hline & Disc jockey, espíquer, radialista, radiorepórter, speaker \\
\hline & Locutor de: rádio e televisão, telejornal, \\
\hline & Disc jockey, espíquer, radialista, radiorrepórter, speaker \\
\hline \multirow{26}{*}{ 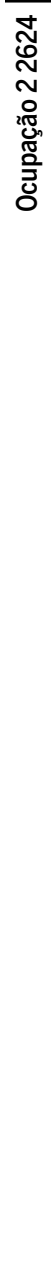 } & Arranjador de orquestra, artista lírico, concertista, orquestrador, sinfonista, solfista \\
\hline & Auxiliar de maestro (em concerto ou orquestra sinfônica, filarmônica, de câmara) \\
\hline & Baixista, bandolinista (músico) (em concerto ou orquestra sinfônica, filarmônica, de câmara) \\
\hline & Baixo, barítono, contralto, soprano, tenor, tenorino (cantor de música clássica, erudita) \\
\hline & Bandurrista, banjoísta, bateria (em concerto ou orquestra sinfônica, filarmônica, de câmara) \\
\hline & Baterista, citarista, clarinetista (em concerto ou orquestra sinfônica, filarmônica, de câmara) \\
\hline & Cantor de: ópera, teatro \\
\hline & Cantor lírico (música clássica, erudita) \\
\hline & Clavecinista, contrabaixista (em concerto ou orquestra sinfônica, filarmônica, de câmara) \\
\hline & Componista, compositor de música clássica, erudita \\
\hline & Compositor, coordenador musical clássico, erudito \\
\hline & Co-spalla de orquestra \\
\hline & Cravista, fagorista, flauteiro (em concerto ou orquestra sinfônica, filarmônica, de câmara) \\
\hline & Flautista, gaiteiro, gaitista (em concerto ou orquestra sinfônica, filarmônica, de câmara) \\
\hline & Guitarrista, harpista (em concerto ou orquestra sinfônica, filarmônica, de câmara) \\
\hline & Harmonista, harmonizador, melodista, melógrafo (música clássica, erudita) \\
\hline & Instrumentista (músico) (em concerto ou orquestra sinfônica, filarmônica, de câmara) \\
\hline & Letrista (composições musicais clássicas, eruditas) \\
\hline & Maestrina, maestro, musicista (em concerto ou orquestra sinfônica, filarmônica, de câmara) \\
\hline & Músico, oboísta, ocarinista (em concerto ou orquestra sinfônica, filarmônica, de câmara) \\
\hline & Organeiro, organista (em concerto ou orquestra sinfônica, filarmônica, de câmara) \\
\hline & Pandeirista, tecladista (músico) (em concerto ou orquestra sinfônica, filarmônica, de câmara) \\
\hline & Percussionista, pianista (em concerto ou orquestra sinfônica, filarmônica, de câmara) \\
\hline & Pistonista, rabequista (em concerto ou orquestra sinfônica, filarmônica, de câmara) \\
\hline & Professor regente (em concerto ou orquestra sinfônica, filarmônica, de câmara) \\
\hline & Regente (maestro) - incl. Auxiliar (em concerto ou orquestra sinfônica, filarmônica, de câmara) \\
\hline
\end{tabular}


Quadro A1 (continuação)

\section{Descrição das atividades}

స్ర

Regente de: afinação, orquestra (em concerto ou orquestra sinfônica, filarmônica, de câmara)

Saxofonista, timbaleiro (em concerto ou orquestra sinfônica, filarmônica, de câmara)

Spalla (solista) de orquestra

Trombetista, trombonista (em concerto ou orquestra sinfônica, filarmônica, de câmara)

Trompetista, trompista (em concerto ou orquestra sinfônica, filarmônica, de câmara)

Trompetista, violeiro (em concerto ou orquestra sinfônica, filarmônica, de câmara)

Violinista, violoncelista (em concerto ou orquestra sinfônica, filarmônica, de câmara)

Acordeonista, adufeiro, cançonetista, charangueiro, charanguista, sanfoneiro,

Baixista, bateria (músico) - excl. em concerto ou orquestra sinfônica, filarmônica, de câmara)

Baixo, barítono, contralto, soprano, tenor, tenorino (cantor de grupo, coral)

Bandolinista, bandurrista - excl. em concerto ou orquestra sinfônica, filarmônica, de câmara)

Banjoísta, baterista - excl. em concerto ou orquestra sinfônica, filarmônica, de câmara

Cantador: de viola, em diversões

Cantor de: rádio, televisão, música popular

Citarista, clarinetista - excl. em concerto ou orquestra sinfônica, filarmônica, de câmara

Clavecinista, cravista - excl. em concerto ou orquestra sinfônica, filarmônica, de câmara

Componista, compositor de música popular

Compositor, coordenador musical popular

Corista, fadista (cantor)

contrabaixista, fagorista - excl. em concerto ou orquestra sinfônica, filarmônica, de câmara

Fadista, sanfonista (músico)

Flauteiro, flautista - excl. em concerto ou orquestra sinfônica, filarmônica, de câmara

Gaiteiro, gaitista - excl. em concerto ou orquestra sinfônica, filarmônica, de câmara

Guitarrista, harpista - excl. em concerto ou orquestra sinfônica, filarmônica, de câmara

Harmonista, harmonizador, melodista, melógrafo, letrista (música popular)

Instrumentista (músico) - excl. em concerto ou orquestra sinfônica, filarmônica, de câmara

Maestrina, maestro - excl. em concerto ou orquestra sinfônica, filarmônica, de câmara

Maestro, regente de: banda de música, grupo coral - incl. auxiliar

Menestrel, músico popular, tocador de sanfona

Musicista, músico - excl. em concerto ou orquestra sinfônica, filarmônica, de câmara

Oboísta, ocarinista - excl. em concerto ou orquestra sinfônica, filarmônica, de câmara

Organeiro, organista - excl. em concerto ou orquestra sinfônica, filarmônica, de câmara

Pandeirista (músico) - excl. em concerto ou orquestra sinfônica, filarmônica, de câmara

Percussionista, pianista - excl. em concerto ou orquestra sinfônica, filarmônica, de câmara 
Quadro A1 (continuação)

\begin{tabular}{|c|c|}
\hline & Descrição das atividades \\
\hline \multirow{10}{*}{ 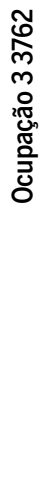 } & Pistonista, rabequista - excl. em concerto ou orquestra sinfônica, filarmônica, de câmara \\
\hline & Professor regente - excl. em concerto ou orquestra sinfônica, filarmônica, de câmara \\
\hline & Regente (maestro) - excl. em concerto ou orquestra sinfônica, filarmônica, de câmara \\
\hline & Regente de afinação - excl. em concerto ou orquestra sinfônica, filarmônica, de câmara \\
\hline & Saxofonista, trompista - excl. em concerto ou orquestra sinfônica, filarmônica, de câmara \\
\hline & Tecladista (músico) - excl. em concerto ou orquestra sinfônica, filarmônica, de câmara \\
\hline & Timbaleiro, trombetista - excl. em concerto ou orquestra sinfônica, filarmônica, de câmara \\
\hline & Trombonista, trompetista - excl. em concerto ou orquestra sinfônica, filarmônica, de câmara) \\
\hline & Trumpetista, violinista - excl. em concerto ou orquestra sinfônica, filarmônica, de câmara \\
\hline & Violeiro, violoncelista - excl. em concerto ou orquestra sinfônica, filarmônica, de câmara \\
\hline
\end{tabular}

Fonte: Relação de Códigos de Ocupação. PNAD. 


\section{APÊNDICE B}

Tabela B1 Equação de seleção

\begin{tabular}{|c|c|c|c|c|c|c|}
\hline \multicolumn{4}{|c|}{ SNP Estimation of Binary-Choice Model } & \multicolumn{2}{|c|}{ Number of obs $=$} & 2421306 \\
\hline & & & & \multicolumn{2}{|c|}{ Wald chi2(3) $=$} & 149686,52 \\
\hline Log pseudolik & $=-1349653$, & & & \multicolumn{2}{|c|}{ Prob $>$ chi $2=$} & 0,0000 \\
\hline participa & Coef. & $\begin{array}{l}\text { Robust } \\
\text { Std. Err. }\end{array}$ & $\mathbf{z}$ & $P>|z|$ & $\begin{array}{r}{[95 \%} \\
\text { Conf. }\end{array}$ & Interval] \\
\hline chefe & ,8997417 & ,0069928 & 128,67 & 0,000 & ,886036 & ,9134474 \\
\hline conjugue & $-1,140421$ & 006651 & $-171,47$ & 0,000 & $-1,153457$ & $-1,127386$ \\
\hline filho & ,0017609 & ,0103232 & 0,17 & 0,865 &,- 0184723 & 0219941 \\
\hline crianca & (offset) & & & & & \\
\hline _cons &, 5775742 & Fixed & & & & \\
\hline SNP coefs: 1 & 1,143439 & ,007595 & 150,55 & 0,000 & 1,128553 & 1,158325 \\
\hline SNP coefs: 2 & ,890561 & ,0105109 & 84,73 & 0,000 & ,86996 & ,911162 \\
\hline SNP coefs: 3 & -,1859484 & 0025138, & $-73,97$ & 0,000 & -,1908754 &,- 1810215 \\
\hline
\end{tabular}

Likelihood ratio test of Probit model against SNP model:

\begin{tabular}{lrrr}
\hline Chi2(1) statistic $=$ & $-21340,49$ & $(\mathrm{p}$-value $=$ & $1)$ \\
\hline Estimated moments of error distribution: & & & \\
\hline Variance $=$ & 3,235501 & Standard Deviation $=$ & 1,79875 \\
\hline $3^{\text {rd }}$ moment $=$ & $-4,513464$ & Skewness $=$ &,- 7755283 \\
\hline $4^{\text {th }}$ moment $=$ & 25,22367 & Kurtosis $=$ & 2,409491 \\
\hline
\end{tabular}

Fonte: Elaboração própria com base nos dados da PNAD. 